\title{
Discriminating between virilizing ovary tumors and ovary hyperthecosis in postmenopausal women: clinical data, hormonal profiles and image studies
}

\author{
V R V Yance 1, *, J A M Marcondes 1, *, M P Rocha1, C R G Barcellos', W S Dantas', \\ A F A Avila ${ }^{2}$, R H Baroni' ${ }^{2}$, F M Carvalho ${ }^{3}$, S A Y Hayashida ${ }^{4}$, B B Mendonca ${ }^{1}$ and \\ S Domenice ${ }^{1}$ \\ 'Unidade de Endocrinologia do Desenvolvimento, Laboratório de Hormônios e Genética Molecular LIM42, \\ Disciplina de Endocrinologia, ${ }^{2}$ Instituto de Radiologia do Hospital das Clínicas, ${ }^{3}$ Departamento de Patologia and \\ ${ }^{4}$ Departamento de Ginecologia do Hospital das Clínicas da Faculdade de Medicina da Universidade de \\ São Paulo, SP, Brasil \\ *(V R V Yance and J A M Marcondes contributed equally as first authors)
}

Correspondence should be addressed to V R V Yance Email

vividosreis@hotmail.com

\begin{abstract}
Background: The presence of virilizing signs associated with high serum androgen levels in postmenopausal women is rare. Virilizing ovarian tumors (VOTs) and ovarian stromal hyperthecosis $(\mathrm{OH})$ are the most common etiologies in virilized postmenopausal women. The differential diagnosis between these two conditions is often difficult. Objective: To evaluate the contribution of clinical features, hormonal profiles and radiological studies to the differential diagnosis of VOT and $\mathrm{OH}$.

Design: A retrospective study.

Setting: A tertiary center.

Main outcome measures: Clinical data, hormonal status (T, E2, LH and FSH), pelvic images (transvaginal sonography and MRI) and anatomopathology were reviewed.

Patients: Thirty-four postmenopausal women with a diagnosis of VOT (13 women) and OH (21 women) were evaluated retrospectively.

Results: Clinical signs of hyperandrogenism were more prevalent in the VOT group than the OH group. Although the VOT group showed higher T and E2 levels and lower gonadotropin levels than the $\mathrm{OH}$ group, a great overlap occurred among the hormone levels. A pelvic MRI provided an accurate differentiation of these two conditions.

Conclusion: In this group of patients, the main features contributing to the differential diagnosis of VOT and $\mathrm{OH}$ were serum levels of testosterone and gonadotropins and the presence of an ovarian nodule identified on the MRI. Although the association of clinical, hormonal and radiological features contributes to the differential diagnosis of these two conditions, histopathological analysis remains the gold standard for the diagnosis of ovarian hyperandrogenism in postmenopausal women.
\end{abstract}

() 2017 European Society of Endocrinology Printed in Great Britain
European Journal of

Endocrinology

(2017) 177, 93-102
Published by Bioscientifica Ltd. 


\section{Introduction}

Several disorders may cause clinical manifestations of hyperandrogenism in postmenopausal women. Despite the presence of clinical features, the altered hormonal profile and accessibility to imaging studies, the differential diagnosis of these disorders remains difficult.

The most common causes of virilization in postmenopausal women are ovarian disorders, virilizing ovarian tumors (VOTs) and ovarian hyperthecosis $(\mathrm{OH})$. Different types of VOTs have been described, especially tumors derived from ovarian stroma, which show a low malignancy potential (1). $\mathrm{OH}$ is characterized by ovarian stromal hyperplasia associated with cellular luteinization (2). The pathophysiology of $\mathrm{OH}$ has not yet been fully elucidated, but it is believed that the stimulation of ovarian stromal cells by elevated gonadotropins in postmenopause, especially luteinizing hormone (LH), may be involved in this process $(3,4,5,6)$. Several authors have observed a significant reduction in serum levels of testosterone after gonadotropin-releasing hormone analog (GnRHa) administration in postmenopausal patients with virilization and an atomopathological study has confirmed the presence of $\mathrm{OH}(7,8)$. These findings indicate a role for continuous ovarian stimulation by elevated gonadotrophins in the pathophysiological process of $\mathrm{OH}$ in menopausal women.

The presence of hyperinsulinemia and insulin resistance is also suggested as factors involved in the pathophysiology of OH. Nagamani et al. observed that women with $\mathrm{OH}$ have a significant degree of insulin resistance, not related to obesity, and suggested that the presence of hyperinsulinemia would act as a stimulatory factor for the production of ovarian androgens, possibly through the induction of stromal luteinization (9). These authors found a significant correlation between peripheral insulin levels and serum levels of testosterone, androstenedione and dihydrotestosterone collected in the ovarian veins. Similar to the findings by Nagamani, other authors have also associated $\mathrm{OH}$ with the presence of insulin resistance and alterations in fasting glucose $(10,11)$.

Some evidence indicates that VOTs are also gonadotropin-dependent conditions (12).

Few studies of hyperandrogenic postmenopausal women have been described. Sarfati et al. evaluated the hormonal profile of 22 postmenopausal women who had various conditions, such as neoplastic diseases, including adrenal and ovarian tumors and non-tumor disorders. Comparison of the hormonal levels in these conditions showed higher testosterone levels and lower FSH levels in women with tumor disorders (13).
Studies of patients with VOTs or $\mathrm{OH}$ are mainly reported as case reports, or the studies have incorporated a small series of patients. This context has contributed to a poor characterization of the virilizing ovarian disorders in postmenopausal women $(5,8,11,12,13,14,15,16,17$, $18,19,20,21,22,23)$.

We report here the results of a retrospective study of a selected series of postmenopausal women with a histopathological diagnosis of VOT or $\mathrm{OH}$ reviewed by an expert pathologist. Clinical data, hormonal profile and pelvic radiological images of 34 women were reviewed.

\section{Patients and methods}

This study was approved by the Ethical Committee of Hospital das Clínicas da Faculdade de Medicina da Universidade de São Paulo (HCFMUSP).

Thirty-four postmenopausal women with histologically confirmed VOT and $\mathrm{OH}$ were identified after a retrospective medical record review. All patients were diagnosed with clinical hyperandrogenism and referred to the Endocrinology Unit of HCFMUSP between 1999 and 2013. Although the study was retrospective, one of the examiners (J A M M) evaluated and followed up with all the patients.

The diagnoses of VOT and $\mathrm{OH}$ were reviewed and confirmed by an expert in gynecological pathology. The diagnosis of the ovarian tumor type was confirmed by specific criteria and classified according to the World Health Organization 2014 (24). The diagnosis of $\mathrm{OH}$ was confirmed by the presence of lutein cells grouped into nests or scattered into the stroma with a typical background of stromal hyperplasia (2).

All women had clinical features, a hormonal profile and an ovarian morphological assessment by pelvic radiological images (transvaginal ultrasound (US) and/ or pelvic magnetic resonance image (MRI)) evaluation. A positron emission tomography/computed tomography (PET-CT) scan was performed in five patients.

The clinical data evaluated were menstrual patterns before menopause, number of pregnancies, age at menopause, age at diagnosis, the rate of disease progression, the elapsed time from the onset of symptoms until diagnosis, clinical signs of hyperandrogenism (hirsutism, androgenic alopecia, clitoromegaly, deepening of the voice and muscle hypertrophy). Hirsutism was defined according to the modified Ferriman-Gallwey score $\geq 8$ (25). Androgenic alopecia was evaluated by the 
Ludwig scale, and the presence or absence of alopecia was used as a criterion of virilization (26). Clitoromegaly was considered as a clitoral body length equal or greater than $2 \mathrm{~cm}$ (27). Deepening of the voice and muscle hypertrophy are subjective criteria. These features were considered present if the patient reported the change, and the conditions were also recognized by two different examiners.

Patients with hyperandrogenism and a diagnosis different from VOT or $\mathrm{OH}$ were not included in the study.

\section{Hormone measurements}

The hormonal evaluation included the measurement of total serum testosterone (T), estradiol (E2), LH and FSH that were measured by immunofluorometric assay (AutoDELFIA, WallacOy, Turku, Finland). The intra- and inter-assay coefficients of variation $(\mathrm{CV})$ were $<5.0 \%$ and $<6.0 \%$ respectively. Hormonal levels were measured on at least two occasions.

The GnRH analog suppression test $(3.75 \mathrm{mg}$ of leuprolide acetate, IM, every 30 days, for 3 months) was performed, and serum levels of LH, FSH, E2 and $\mathrm{T}$ were evaluated before and 30 days after the last GnRHa injection.

\section{Imaging studies}

Ovarian morphology was evaluated by transvaginal ultrasound (US) in all except two women. A pelvic MRI was performed on 16 women (nine women with $\mathrm{OH}$ and seven women with VOT), and the results of 11 images (five women with $\mathrm{OH}$ and six women with VOT) were available for blinded review by a single radiologist (B R H). A PET-CT study was performed on five women (four women with $\mathrm{OH}$ and one woman with VOT).

Ovarian volume $\geq 4.0 \mathrm{~cm}^{3}$ was considered an increased ovary size in postmenopausal women $(28,29)$. The presence of ovarian asymmetry was defined as the largest ovary size greater than or equal to twice the smallest ovary size, and this finding in the imaging studies was suggestive of the presence of an ovarian tumor (30).

\section{Statistical analysis}

Descriptive statistics were performed for each variable, and quantitative results are presented as the mean values \pm S.D. The significance of clinical characteristics was evaluated using Fisher's exact test. A comparison of the quantitative variables between VOT and $\mathrm{OH}$ was performed using Student's $t$-test or Mann-Whitney non-parametric test.

The receiver operating characteristic (ROC) curve was performed to determine the optimal cut-off hormonal values and the sensitivity (Se) and specificity (Sp) of the values for a VOT diagnosis.

\section{Results}

A total of 34 women with a VOT or $\mathrm{OH}$ diagnosis were studied (Table 1). Thirteen women aged 52-77 years were diagnosed with VOT, and 21 women aged $52-80$ years were diagnosed with $\mathrm{OH}$. All tumors were unilateral, and $\mathrm{OH}$ was bilateral in 20 women and unilateral in one patient who had previously submitted to unilateral oophorectomy.

Three women of the VOT group and two women of the $\mathrm{OH}$ group presented with surgical menopause after hysterectomy for myoma. All women studied had a history of monthly menstrual cycles and only two women, one patient in the VOT group and the other patient in the $\mathrm{OH}$ group, reported infertility. Premature ovarian failure (at the age of 33 years) was reported by one patient in the VOT group. The presence of clinical signs of hyperandrogenism prior to menopause was reported by two patients with $\mathrm{OH}$.

The clinical data of the natural history evaluated did not demonstrate clinical significance between the two groups of patients, except for a higher number of pregnancies in the VOT group than that in the $\mathrm{OH}$ group $(P=0.04)$. The elapsed time from the onset of signals and symptoms of the disease until the diagnosis was 4 to 120 months in the VOT group and 12 to 126 months in the $\mathrm{OH}$ group $(P=0.630)$.

All women had hirsutism, and no difference in the hirsutism score between the two groups $(P=0.749)$ was identified. In addition to hirsutism, alopecia was the most frequent hyperandrogenic sign and was present in all women with VOT and in 16 of the 21 women with $\mathrm{OH}(P=0.132)$. The presence of clitoromegaly was not significantly different between the two groups of patients $(P=0.141)$.

The clinical signs such as deepening of the voice $(P<0.001)$ and muscle hypertrophy $(P=0.01)$ were more prevalent in the VOT group than those in the $\mathrm{OH}$ group.

The comparative data of clinical and hormonal parameters are presented in Tables 2 and 3.

There was no difference concerning BMI between the patients with VOT and $\mathrm{OH}(30.8 \pm 5.7$ vs $31.6 \pm 4.4$ 
Table 1 Clinical data of 34 postmenopausal women with ovarian hyperandrogenism.

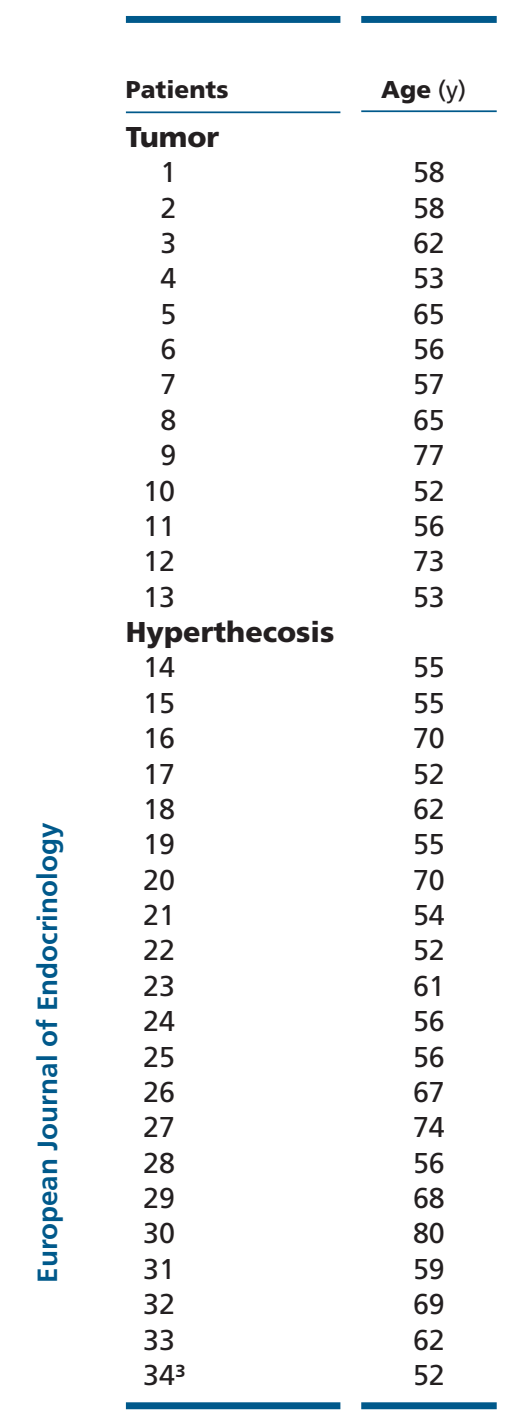
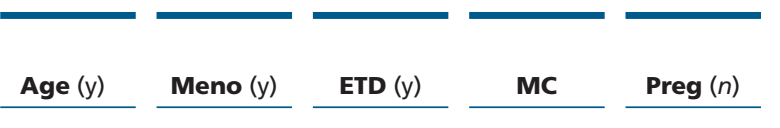

\begin{tabular}{cc}
\hline \multicolumn{1}{c}{ Signs } \\
\hline $\mathrm{H}$ \\
\hline $\mathrm{A}$
\end{tabular}

$\begin{array}{lc}50 & 8 \\ 45 & 10 \\ 51 & 8 \\ 40^{1} & 8 \\ 45 & 4 \\ 33^{2} & 2 \\ 38^{1} & 3 \\ 43^{1} & 0.3 \\ 55 & 10 \\ 45 & 1 \\ 48 & 9 \\ 46 & 4 \\ 45 & 3\end{array}$

$M$
$M$
$M$
$M$
$M$
$M$
$M$
$M$
$M$
$M$
$M$
$M$
$M$

2
2
7
3
6
3
3
6
12
2
5
5
3

15

23

18

18
23

23
14

14
20

20

22

11

11
31

31
20

20
14

14
10
25

+
+
+
+
+
+
+
+
+
+
+
+
+

+
+
+

$52 \quad 3$

Meno, menopause; ETD, elapsed time until diagnoses; MC, menstrual cycle; M, monthly; Preg ( $n$ ), number of pregnancies; $H$, hirsutism; A, androgenic alopecia; DV, deepening of the voice; C, clitoromegaly; $\mathrm{MH}$, muscle hypertrophy; $\mathrm{N}$, not described; ${ }^{1}$ History of hysterectomy due to myomas; ${ }^{2} \mathrm{History}$ of early menopause at 33 years of age; ${ }^{3 R i g h t}$ oophorectomy at 38 years of age because of hirsutism and unknown pathological diagnosis.

respectively, $P=0.653$ ) (Table 2 ). Obesity and overweight were diagnosed in $84 \%$ of women with VOT and in $95 \%$ of women with $\mathrm{OH}$.

Six of 13 women with VOT and 15 of 21 women with $\mathrm{OH}$ were diagnosed with type 2 diabetes (DM2) at the first visit to investigate the clinical picture of hyperandrogenism. No statistical significance was observed between VOT and $\mathrm{OH}$ patients concerning fasting glucose and fasting insulin.

\section{Hormonal profile}

The hormonal profile revealed significant differences in the $\mathrm{T}$ and $\mathrm{E}_{2}$ mean levels; higher levels were observed in the VOT group than that in the OH group $(560 \mathrm{ng} / \mathrm{dL}$ vs $182 \mathrm{ng} / \mathrm{dL}, P<0.01$ and $65 \mathrm{pg} / \mathrm{mL}$ vs $26 \mathrm{pg} / \mathrm{mL}, P<0.01$ respectively). Additionally, the $\mathrm{LH}$ and FSH mean levels were higher in the $\mathrm{OH}$ group than that in the VOT group (25 IU/L vs $9 \mathrm{IU} / \mathrm{L}, P<0.001$ and $45 \mathrm{IU} / \mathrm{L}$ vs $14 \mathrm{IU} / \mathrm{L}$, $P<0.001$ respectively).

The best cut-off value for hormonal levels to differentiate VOT from $\mathrm{OH}$ in our patient groups was $\mathrm{T}>312.5 \mathrm{ng} / \mathrm{dL} \quad(\mathrm{Se}=76.9 \% ; \quad \mathrm{Sp}=90.5 \%), \quad \mathrm{LH}<10.8$ IU/L $\quad(\mathrm{Se}=76.9 \% ; \quad \mathrm{Sp}=90.5 \%)$ and $\quad \mathrm{FSH}<22.3 \mathrm{IU} / \mathrm{dL}$ $(\mathrm{Se}=77 \% ; \mathrm{Sp}=85.7 \%)$.

Two women in the VOT group and 13 women in the $\mathrm{OH}$ group were submitted to a GnRHa suppression test, and the suppression of the gonadotropic axis was 
Table 2 Comparison of the clinical profile of patients diagnosed with a virilizing ovarian tumor and ovarian hyperthecosis.

\begin{tabular}{|c|c|c|c|}
\hline & VOT & OH & $P$ value \\
\hline Age at diagnosis (y) & $60.4 \pm 7.8$ & $61.2 \pm 8.1$ & $0.943 *$ \\
\hline Onset of symptoms (y) & $55.1 \pm 8.1$ & $53.7 \pm 11.6$ & $0.943^{*}$ \\
\hline $\begin{array}{l}\text { Elapsed time until } \\
\text { diagnosis }(\mathrm{y})\end{array}$ & $5.4 \pm 3.5$ & $7.4 \pm 7.5$ & $0.630 *$ \\
\hline Number of pregnancies & $4.5 \pm 2.8$ & $2.7 \pm 2.3$ & $0.048^{*}$ \\
\hline Hirsutism & $13 / 13$ & $20 / 21$ & $>0.999^{\&}$ \\
\hline Androgenic alopecia & $13 / 13$ & $16 / 21$ & $0.132^{\&}$ \\
\hline Clitoromegaly & $11 /$ & $11 / 19$ & $0.141^{\&}$ \\
\hline Deepening of the voice & $11 / 13$ & $2 / 21$ & $<0.001^{\&}$ \\
\hline Muscle hypertrophy & $8 / 12$ & $4 / 21$ & $0.010^{\&}$ \\
\hline Body mass index $\left(\mathrm{kg} / \mathrm{m}^{2}\right)$ & $30.8 \pm 5.7$ & $31.6 \pm 4.4$ & $0.653 * *$ \\
\hline
\end{tabular}

VOT, virilizingovarian tumor; $\mathrm{OH}$, ovarian hyperthecosis;

$* P$ values from the Mann-Whitney test; ${ }^{*} P$ values from Student's $t$-test;

\& $P$ values from Fisher's exact test.

observed in all 15 subjects (the median of LH and FSH after the GnRHa test in VOT vs OH groups were $1.05 \mathrm{IU} / \mathrm{L}$ and $9.7 \mathrm{IU} / \mathrm{L}$ vs $0.87 \mathrm{IU} / \mathrm{L}$ and $8.0 \mathrm{IU} / \mathrm{L}$ respectively). The median T levels were reduced to a minimum of $50 \%$ after the GnRHa test (from $538 \mathrm{ng} / \mathrm{dL}$ to $12.5 \mathrm{ng} / \mathrm{dL}$ for the VOT group and from $182.4 \mathrm{ng} / \mathrm{dL}$ to $12.7 \mathrm{ng} / \mathrm{dL}$ for the $\mathrm{OH}$ group).

\section{Radiological characteristics}

In the group of patients with VOT, transvaginal US correctly identified the side of the ovarian tumor in five of eleven women (45.5\%). The most common transvaginal US finding was a complex cyst present in three of the five patients; in each of the other two patients, a solid nodule was identified. In this group of hyperandrogenic postmenopausal women, the transvaginal US accuracy of the VOT diagnosis was $48 \%$ (Table 4 ).

In the group of $\mathrm{OH}$ patients, transvaginal US identified the ovaries bilaterally in 14 women, unilaterally in six women (one patient previously underwent an oophorectomy), and the ovaries were not identified in one patient. Bilateral increases in the size of the ovaries were observed in eight women diagnosed with $\mathrm{OH}$. The presence of a unilateral solid nodule was observed in three patients (one patient previously underwent an oophorectomy), a bilateral solid nodule was observed in four patients, and asymmetric ovaries without solid or complex cystic lesions were observed in one patient. All seven ovarian nodules detected by transvaginal US in the $\mathrm{OH}$ patients were not histologically confirmed (Table 5).

Pelvic MRIs of six patients with VOT were reviewed, and in all patients, nodules were identified on the reviewed images, except in one patient who had a steroidic cell tumor (patient 9). The presence of five unilateral nodules (four solid lesions and one solid-cystic lesion) was confirmed; four nodules presented in a hypervascular pattern. The patient without ovarian nodules on MRI presented with asymmetrical ovaries, a suggestive criterion of tumor presence (Table 4).

A hypointense signal of T1-weighted sequences with enhancement after contrast was observed in all ovarian lesions of VOT patients. The signal intensity on T2-weighted sequences was variable (a hyperintense signal in two nodules, a hypointense signal in one nodule and different intensity signals in the other two nodules).

In the $\mathrm{OH}$ group, an MRI was performed in nine women, but only five images were available for review. In this group of patients, a pelvic MRI revealed the presence of a unilateral nodule in one patient, an asymmetric ovary

Table 3 Comparison of the hormonal profile and the fasting glucose and insulin levels of patients diagnosed with a virilizing ovarian tumor and ovarian hyperthecosis.

\begin{tabular}{|c|c|c|c|c|c|}
\hline \multirow[b]{2}{*}{ Hormones } & \multicolumn{2}{|c|}{ Virilizing ovarian tumor } & \multicolumn{2}{|c|}{ Hyperthecosis } & \multirow[b]{2}{*}{$P$ value } \\
\hline & Mean $( \pm S D)$ & Median & Mean $( \pm \mathrm{SD})$ & Median & \\
\hline Testosterone (ng/dL) & $560 \pm 434$ & 493 & $182 \pm 89$ & 173 & $<0.001$ \\
\hline Estradiol (pg/mL) & $65 \pm 64$ & 45 & $26 \pm 9$ & 25 & $<0.001$ \\
\hline LH (IU/L) & $9 \pm 9$ & 8 & $25 \pm 12$ & 23 & $<0.001$ \\
\hline FSH (IU/L) & $14 \pm 10$ & 10 & $45 \pm 25$ & 40 & $<0.001$ \\
\hline Androstenedione $(\mathrm{ng} / \mathrm{mL})$ & $3 \pm 2$ & 2 & $2.5 \pm 1.7$ & 2 & 0.788 \\
\hline DHEAS (ng/mL) & $974 \pm 531$ & 889 & $749 \pm 447$ & 1 & 0.222 \\
\hline $170 \mathrm{HP}(\mathrm{ng} / \mathrm{mL})$ & $3 \pm 4$ & 2 & $1.4 \pm 0.9$ & 1 & 0.146 \\
\hline Insulin $(\mu \mathrm{U} / \mathrm{mL})$ & $17 \pm 10$ & 13 & $20 \pm 10$ & 18 & 0.520 \\
\hline Glucose (mg/dL) & $118 \pm 61$ & 96 & $122 \pm 34$ & 112 & 0.820 \\
\hline
\end{tabular}

* $P$ values from the Mann-Whitney test; Conversion factors to $\mathrm{SI}$ units: $\mathrm{T}$, $\mathrm{ng} / \mathrm{dL}$ to $\mathrm{nmol} / \mathrm{L}$, multiply by $0.0347 ; \mathrm{E}_{2}$, $\mathrm{pg} / \mathrm{mL}$ to $\mathrm{pmol} / \mathrm{L}$, $\mathrm{multiply} \mathrm{by} 3.671$; Androstenedione, $\mathrm{ng} / \mathrm{mL}$ to $\mathrm{nmol} / \mathrm{L}$, multiply by 3.18 ; DHEAS, $\mathrm{ng} / \mathrm{mL}$ to $\mu \mathrm{mol} / \mathrm{L}$, multiply by $0.0371 ;$ Insulin, $\mu \mathrm{U} / \mathrm{mL}$ to $\mathrm{pmol} / \mathrm{L}$, multiply by 7.175 ; Glucose, $\mathrm{mg} / \mathrm{dL}$ to $\mathrm{mmol} / \mathrm{L}$, multiply by 0.0555 . 
Table 4 Pelvic transvaginal ultrasound and magnetic resonance comparison and correlation with anatomopathology of patients with an ovarian androgen-producing tumor.

\begin{tabular}{|c|c|c|c|c|c|c|c|}
\hline \multirow[b]{2}{*}{ Pt } & \multicolumn{2}{|c|}{ Pelvic ultrasound } & \multicolumn{2}{|c|}{ Magnetic resonance of pelvis } & \multicolumn{3}{|c|}{ Anatomopathology } \\
\hline & $\mathrm{RO}\left(\mathrm{cm}^{3}\right)$ & $\mathrm{LO}\left(\mathrm{cm}^{3}\right)$ & $\mathrm{RO}\left(\mathrm{cm}^{3}\right)$ & $\mathrm{LO}\left(\mathrm{cm}^{3}\right)$ & $\mathrm{RO}\left(\mathrm{cm}^{3}\right)$ & $\mathrm{LO}\left(\mathrm{cm}^{3}\right)$ & Size/kind \\
\hline 1 & 5.2 & 8.3 & $\begin{array}{l}6.4 \text { (solid nodule, } \\
2.0 \mathrm{~cm} \text { ) }\end{array}$ & 4.5 & Leydig $\mathrm{Tu} \pm \mathrm{OH}$ & $\mathrm{OH}$ & $1.8 \mathrm{~cm} / \mathrm{solid}$ \\
\hline 2 & 9.0 & 7.0 & $\begin{array}{l}8.4 \text { (solid nodule, } \\
2.4 \mathrm{~cm} \text { ) }\end{array}$ & 0.8 & Leydig $\mathrm{Tu} \pm \mathrm{OH}$ & $\mathrm{OH}$ & NM/solid \\
\hline 3 & 10.0 & 6.7 & - & - & $\mathrm{OH}$ & Leydig Tu+OH & $2.0 \mathrm{~cm} / \mathrm{solid}$ \\
\hline 4* & - & - & - & - & $\mathrm{OH}$ & Leydig $\mathrm{Tu}+\mathrm{OH}$ & $2.5 \mathrm{~cm} / \mathrm{solid}$ \\
\hline 5 & $\begin{array}{l}374.0 \text { (Cyst, } 9.6 \mathrm{~cm} \\
\text { with hypervasc } \\
\text { solid vegetation) }\end{array}$ & 1.4 & $\begin{array}{l}302.3 \text { (solid-cystic, } \\
3.2 \mathrm{~cm} \text { ) }\end{array}$ & 3.2 & Hilar Leydig Tu & $\begin{array}{l}\text { Not surgically } \\
\text { located }\end{array}$ & $4.0 \mathrm{~cm} /$ cystic \\
\hline 6 & Not visualized & $\uparrow$ & - & - & $\mathrm{OH}$ & $\begin{array}{l}\text { Steroidic cell Tu } \\
\mathrm{NOE}+\mathrm{OH}\end{array}$ & NM/solid \\
\hline 7 & $\begin{array}{l}\text { Previous surgical } \\
\text { removal }\end{array}$ & $\begin{array}{l}31.0 \\
\text { (complex } \\
\text { cyst, } \\
4.3 \mathrm{~cm}, \\
\text { hypovasc) }\end{array}$ & - & - & $\begin{array}{l}\text { Previous surgical } \\
\text { removal }\end{array}$ & $\begin{array}{l}\text { Steroidic cell Tu } \\
\text { NOE }\end{array}$ & $5.0 \mathrm{~cm} / \mathrm{solid}$ \\
\hline 8 & - & - & 0.8 & $\begin{array}{l}10.1 \text { (solid } \\
\text { nodule, } 2.4 \mathrm{~cm} \text {, } \\
\text { hypervasc) }\end{array}$ & $\begin{array}{l}\text { Not surgically } \\
\text { located }\end{array}$ & $\begin{array}{l}\text { Steroidic cell Tu } \\
\text { NOE }\end{array}$ & $3.5 \mathrm{~cm} / \mathrm{solid}$ \\
\hline 9 & 12.0 & 8.0 & 9.7 & 19.6 & $\mathrm{OH}$ & $\begin{array}{l}\text { Steroidic cell Tu } \\
\text { NOE }\end{array}$ & NM/solid \\
\hline 10 & $\begin{array}{l}16.0 \text { (solid nodule, } \\
2.6 \mathrm{~cm} \text {, hypervasc) }\end{array}$ & 3.0 & $\begin{array}{l}24.9 \text { (solid nodule, } \\
2.6 \mathrm{~cm} \text { ) }\end{array}$ & 10.5 & Thecoma $\pm \mathrm{OH}$ & $\mathrm{OH}$ & $2.5 \mathrm{~cm} / \mathrm{solid}$ \\
\hline 11 & Not visualized & $\begin{array}{l}\text { Not } \\
\text { visualized }\end{array}$ & - & - & $\begin{array}{l}\text { Sertoli-Leydig Tu } \\
(\mathrm{MD})+\mathrm{OH}\end{array}$ & $\mathrm{OH}$ & $1.8 \mathrm{~cm} / \mathrm{solid}$ \\
\hline 12 & $\begin{array}{l}10.3 \text { (solid nodule, } \\
1.6 \mathrm{~cm} \text { ) }\end{array}$ & 1.8 & - & - & $\begin{array}{l}\text { Sertoli-Leydig Tu } \\
(\mathrm{MD})+\mathrm{OH}\end{array}$ & $\mathrm{OH}$ & $4.5 \mathrm{~cm} / \mathrm{solid}$ \\
\hline 13 & $\begin{array}{l}22.5 \text { (cyst with } \\
\text { parietal } \\
\text { vegetation of } \\
2.2 \mathrm{~cm} \text { ) }\end{array}$ & $\begin{array}{l}\text { Not } \\
\text { visualized }\end{array}$ & 30.0 & Not visualized & $\begin{array}{l}\text { Sertoli-Leydig Tu } \\
\text { (MD) }+\mathrm{OH}\end{array}$ & Normal & $4.0 \mathrm{~cm} /$ solid \\
\hline
\end{tabular}

Pt, patients; RO, right ovary; LO, left ovary; Size/Type, size and histological type of tumor; Tu, tumor; OH, ovary hyperthecosis; NOS, not otherwise specified; NM, not measured; MD, moderately differentiated; Hypovasc, hypovascularized; Hypervasc, hypervascularized; normovasc, normovascularized; *, no image available.

in one patient and ovaries with increased size bilaterally in three women (Table 5). A hypointense signal on T2and T1-weighted sequences without enhancement after contrast was observed in the ovarian parenchyma of $\mathrm{OH}$ patients, except in the patient (patient 14) that presented with a solid nodule with enhancement after contrast, a feature observed in the tumor lesions.

In this group of hyperandrogenic postmenopausal women, the accuracy of the pelvic MRI in diagnosing VOT was $82 \%(P=0.01)$.

PET-CT was performed on five women (one VOT and four $\mathrm{OH}$ ) and was able to detect the ovarian lesion in the single VOT patient and was negative in all four women diagnosed with $\mathrm{OH}$.

\section{Discussion}

Hyperandrogenism in postmenopausal women is a rare condition that encompasses a broad spectrum of entities. The differential diagnosis of androgen excess syndrome in postmenopausal women remains very challenging, because these diseases may present several similarities in the clinical manifestations and hormonal profile.

Clinical features and the hormonal profile of 22 postmenopausal women with biochemical hyperandrogenism were reported by Sarfati et al. (13) Although, the etiology of hyperandrogenism in these women was extremely heterogeneous, including benign and malignant diseases of adrenal and ovarian origin, 
Table 5 Pelvic transvaginal ultrasound and magnetic resonance comparison and correlation with anatomopathology of patients with hyperthecosis.

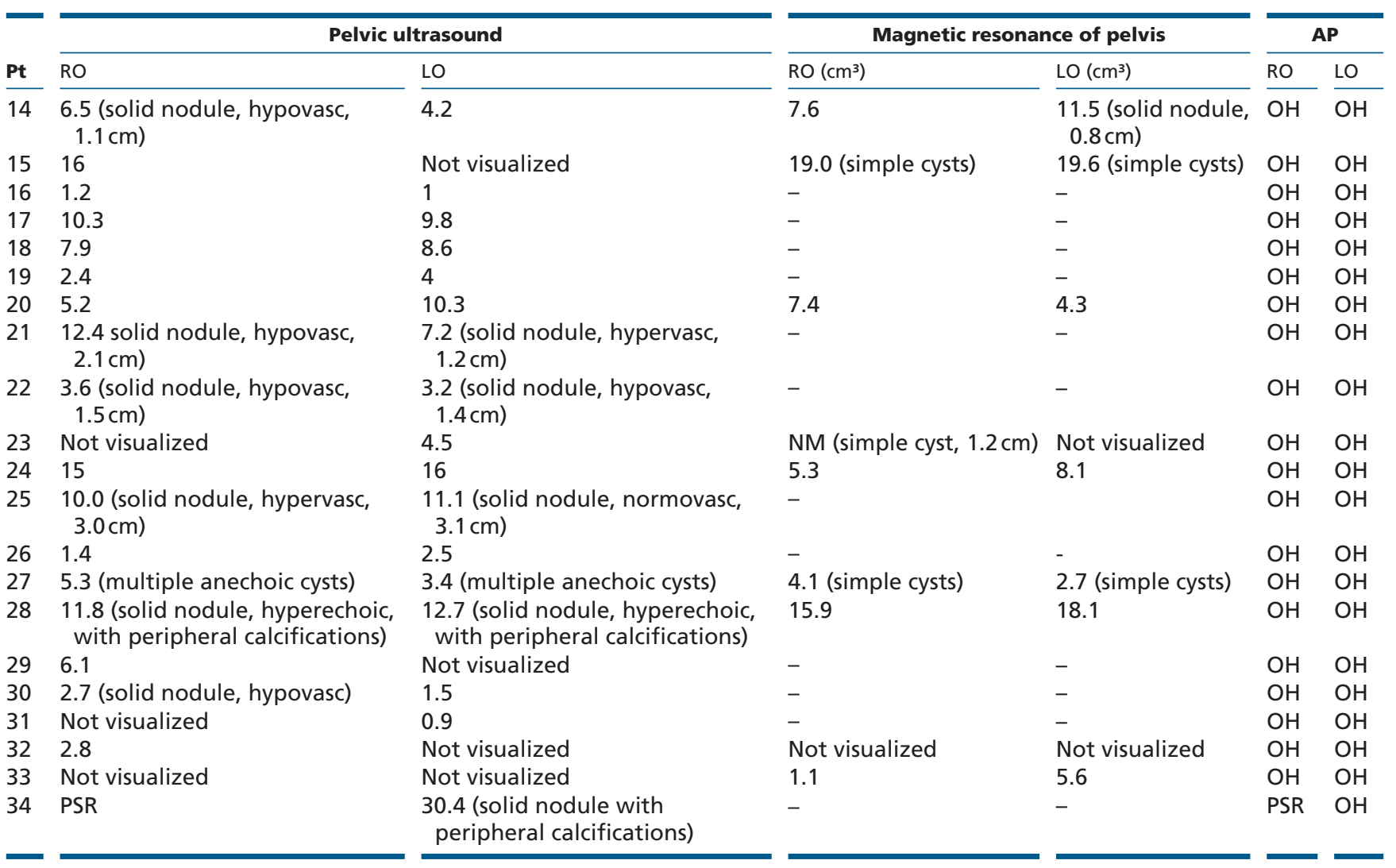

Pt, patients; RO, right ovary; LO, left ovary; AP, anatomophatology; OH, ovary hyperthecosis; NM, not measured; Hypovasc, hypovascularized; Hypervasc, hypervacularized; Normovasc, normovascularized; PSR, previous surgical removal.

it was suggested that testosterone and FSH levels could be useful parameters in the discrimination between androgen-secreting tumors and other diseases evaluated in the study.

Clinical data of 34 postmenopausal women, including the age at diagnosis, the age of onset of symptoms, the elapsed time from the onset of symptoms until diagnosis, or the rate of disease progression were not different between the VOT and $\mathrm{OH}$ groups of patients, which was a similar finding in the study by Sarfati et al. These findings ruled out the notion that the time to onset of symptoms and the rapidly worsening signs of virilization must be considered as important predictive factors of virilizing ovarian tumors $(14,31)$.

A prior history of a normal menstrual cycle and normal fertility in our patients were antagonistic features to the hypothesis that the origin of the postmenopausal $\mathrm{OH}$ might be an evolved form of PCOS (27). A few reports described women with premenopausal $\mathrm{OH}$ and the presence of menstrual disturbances (28).
Signs of virilization in postmenopausal women are uncommon, and the presence of these features should prompt an immediate investigation of a tumor source of androgen excess. Moreover, in virilized postmenopausal women, the $\mathrm{OH}$ must be considered an important differential diagnosis $(12,32)$. The comparative data of clinical features in our cohort showed that the signs of virilization were more prevalent in VOT than those in $\mathrm{OH}$ patients. Although, voice deepening and muscular hypertrophy were more prevalent in the VOT group than those in the $\mathrm{OH}$ group, these signs were subjectively assessed and slight variations in these parameters could not be identified.

The excess of androgen have been associated with increased advanced glycation end-products (AGEs), metabolic syndrome and increased risk of cardiovascular disease (33). However, these findings were not confirmed in recent studies $(34,35,36)$. In our study, $61.7 \%$ of postmenopausal women with hyperandrogenism had DM2, but there was no statistically significant difference 
in fasting glucose and insulin values between the VOT and $\mathrm{OH}$ groups.

Differences were also described regarding the hormonal profile in postmenopausal women with tumor and non-tumor disease. Sarfati et al. reported that $\mathrm{T}$ and $\mathrm{E}_{2}$ serum levels were significantly higher in women with virilizing tumor disease, whereas gonadotropin levels were significantly lower in these patients (13).

We identified this same hormonal pattern in the comparative study between the groups of VOT and $\mathrm{OH}$ patients. Women with a diagnosis of VOT had higher $\mathrm{T}$ levels than the $\mathrm{OH}$ patients, and the gonadotropins levels were lower in the VOT group than those in the $\mathrm{OH}$ group. However, an important overlap was observed between the $\mathrm{T}$ levels and the gonadotropin levels in both groups of patients.

In the literature, a total testosterone level $>200 \mathrm{ng} /$ dL has been advocated as a cut-off level for increased VOT suspicion $(31,37)$. However, this cut-off level has revealed a low diagnostic accuracy (31). Moreover, it is not clear if this cut-off value could be used in the postmenopausal women group, considering that few studies have been conducted in women in this age group with hyperandrogenic conditions. In the group of patients with $\mathrm{OH}$, we identified seven $(33 \%)$ women that presented with $\mathrm{T}$ levels higher than $200 \mathrm{ng} / \mathrm{dL}$, which is an unlikely finding.

In our study, the best discriminating criteria for the presence of tumor were the levels of $\mathrm{T}>312.5 \mathrm{ng} / \mathrm{dL}$ $(\mathrm{Se}=76.9 \%, \mathrm{Sp}=90.5 \%)$ and $\mathrm{LH}<10.8 \mathrm{IU} / \mathrm{L} \quad(\mathrm{Se}=76.9 \%$, $\mathrm{Sp}=90.5 \%)$, followed by $\mathrm{FSH}<22.3 \mathrm{IU} / \mathrm{L} \quad(\mathrm{Se}=77 \%$, $\mathrm{Sp}=85.7 \%)$.

The GnRHa suppression test could be useful in differentiating an adrenal from an ovarian source of hyperandrogenemia (12), although it has not been a useful tool in the differentiation between VOT and $\mathrm{OH}$, as both diseases present with the suppression of the gonadal axis $(7,11,12,19)$. All fifteen patients tested in this study showed a decrease in LH and FSH levels after the GnRHa test, and a minimum of 50\% reduction in T levels was observed in all of these patients. Two women in the VOT group had suppressed gonadotropin basal levels, which were not observed in the $\mathrm{OH}$ group. These findings suggest the involvement of gonadotropins in the pathophysiological mechanism of these two conditions, and an incomplete autonomy of VOT cells.

Despite the fact of mean testosterone ( $\mathrm{T}=182 \pm 89.5 \mathrm{ng} /$ $\mathrm{dL})$ and mean FSH ( $\mathrm{FSH}=45 \pm 24.8 \mathrm{IU} / \mathrm{L})$ levels in the group of $\mathrm{OH}$ patients were elevated, the estradiol levels were only discretely increased $\left(\mathrm{E}_{2}=26 \pm 8.7 \mathrm{pg} / \mathrm{mL}\right.$; postmenopausal women $\mathrm{NV}<25 \mathrm{pg} / \mathrm{mL}$ ). This condition may be explained because in the postmenopausal women the ovarian aromatase activity is decreased when compared to women during the reproductive years $(38,39)$. The activity of aromatase in non-gonadal tissues, that has an important role in estrogen synthesis in postmenopausal women, is not dependent of the FSH levels (39).

Conventional radiological criteria have established that the identification of a significant asymmetry between the ovarian volumes or the presence of a nodule in one of the ovaries may indicate the presence of an ovarian tumor, whereas the bilateral increased ovarian volume is characteristic of the presence of $\mathrm{OH}$. However, some cases reported in the literature have demonstrated the presence of unilateral $\mathrm{OH}$, as well as the presence of bilateral tumors $(22,40,41)$. The absence of nodules or complex cysts does not exclude the presence of small tumors, and the presence of an ovarian nodule does not confirm the presence of a tumor; some of these conditions were identified in our patients.

Unlike the transvaginal US, the pelvic MRI showed good sensitivity (83\%), specificity (80\%) and accuracy $(82 \%)$ in the diagnosis of VOT in this group of hyperandrogenic women. The characteristic image of the VOT observed in the pelvic MRI was a solid nodule with a hypointense signal on T1 with enhancement after contrast. Differently, in patients with $\mathrm{OH}$, the ovarian characteristic MRI image was a bilateral enlargement of the ovary with a hypointense signal on T2 and T1 without enhancement after contrast.

The experience with PET-CT in virilizing syndromes in postmenopausal women is limited (42). Although the result was positive in our single patient, the literature is controversial $(20,43,44)$. Moreover, this is the first report about the employment of PET-CT in women with hyperthecosis and suggests that this method is a compromised one in discriminating between VOT and $\mathrm{OH}$, at least in postmenopausal women. However, this result needs to be confirmed by other studies.

The differential diagnosis between these two conditions is often difficult and bilateral oophorectomy is still the treatment of choice in postmenopausal women with ovarian hyperandrogenism. Clinical, hormonal and pelvic MRI findings suggestive of $\mathrm{OH}$ may help consider the option of GnRH analog treatment for women who refuse surgery or have high- risk surgery (33). 


\section{Conclusion}

In this group of patients, the main features contributing to the differential diagnosis between VOT and $\mathrm{OH}$ were serum levels of testosterone and gonadotropins and the presence of an ovarian nodule on the pelvic MRI. Although the association of clinical, hormonal and radiological features contributes to the differential diagnosis between these two conditions, the histopathological analysis remains the gold standard for the differential diagnosis of ovarian hyperandrogenism in postmenopausal women.

\section{Declaration of interest}

The authors declare that there is no conflict of interest that could be perceived as prejudicing the impartiality in this study.

\section{Funding}

This work was supported by the Conselho Nacional de Desenvolvimento Científico e Tecnológico- CNPq (grant numbers 158332/2014-8);

\section{References}

1 Oliva E \& Young RH. Endocrine pathology of the ovary: in tribute to Robert E Scully, MD. Endocrine Pathology 201425 102-119. (doi:10.1007/s12022-013-9285-4)

2 Scully R. Tumors of the Ovary, Maldeveloped Gonads, Fallopian Tube, and Broad Ligament. In Atlas of Tumor Pathology., edn 3, pp 413-415. Ed H WH. Washington DC: Armed Forces Institute of Pathology 1996.

3 Adashi E. The climacteric ovary as a functional gonadotropin-driven androgen-producing gland. Fertility and Sterility 199462 20-27. (doi:10.1016/S0015-0282(16)56810-1)

4 Nagamani M, Osuampke C \& Kelver ME. Increased bioactive luteinizing hormone levels and bio/immuno ratio in women with hyperthecosis of the ovaries: possible role of hyperinsulinemia. Journal of Clinical Endocrinology and Metabolism 199984 1685-1689. (doi:10.1210/jc.84.5.1685)

5 Krug E \& Berga SL. Postmenopausal hyperthecosis: functional dysregulation of androgenesis in climacteric ovary. Obstetrics \& Gynecology 200299 893-897. (doi:10.1097/00006250-20020500100009)

6 Nakano R, Shima K, Yamoto M, Kobayashi M, Nishimori K \& Hiraoka $\mathrm{J}$. Binding sites for gonadotropins in human postmenopausal ovaries. Obstetrics \& Gynecology 198973 196-200.

7 Pascale MM, Pugeat M, Roberts M, Rousset H, Dechaud H, DutrieuxBerger N \& Tourniaire J. Androgen suppressive effect of GnRH agonist in ovarian hyperthecosis and virilizing tumours. Clinical Endocrinology 199441 571-576. (doi:10.1111/j.1365-2265.1994.tb01820.x)

8 Koroscil TM, Harter SB, Ouweleen J \& Blauer KL. Use of a gonadotropin-releasing hormone agonist in the evaluation of postmenopausal virilization due to ovarian hyperthecosis. A case report. Journal of Reproductive Medicine 199641 259-262.

9 Nagamani M, Van Dinh T \& Kelver ME. Hyperinsulinemia in hyperthecosis of the ovaries. American Journal of Obstetrics \& Gynecology 1986154 384-389. (doi:10.1016/0002-9378(86)90676-9)

10 Vaikkakara S, Al-Ozairi E, Lim E, Advani A, Ball SG, James RA \& Quinton R. The investigation and management of severe hyperandrogenism pre- and postmenopause: non-tumor disease is strongly associated with metabolic syndrome and typically responds to insulin-sensitization with metformin. Gynecological Endocrinology 200824 87-92. (doi:10.1080/09513590701807100)

11 Barth JH, Jenkins M \& Belchetz PE. Ovarian hyperthecosis, diabetes and hirsuties in post-menopausal women. Clinical Endocrinology 1997 46 123-128. (doi:10.1046/j.1365-2265.1997.1050916.x)

12 Marcondes JA, Curi DD, Matsuzaki CN, Barcellos CR, Rocha MP, Hayashida SA \& Baracat EC. Ovarian hyperthecosis in the context of an adrenal incidentaloma in a postmenopausal woman. Arquivos Brasileiros de Endocrinologia \& Metabologia 200852 1184-1188.

13 Sarfati J, Bachelot A, Coussieu C, Meduri G \& Touraine P. Impact of clinical, hormonal, radiological, and immunohistochemical studies on the diagnosis of postmenopausal hyperandrogenism. European Journal of Endocrinology 2011165 779-788. (doi:10.1530/EJE-11-0542)

14 Alpanes M, Gonzalez-Casbas JM, Sanchez J, Pian H \& EscobarMorreale HF. Management of postmenopausal virilization. Journal of Clinical Endocrinology and Metabolism 201297 2584-2588. (doi:10.1210/jc.2012-1683)

15 Braithwaite SS, Erkman-Balis B \& Avila TD. Postmenopausal virilization due to ovarian stromal hyperthecosis. Journal of Clinical Endocrinology and Metabolism 197846 295-300. (doi:10.1210/jcem-46-2-295)

16 Buhler-Christen A, Tischler V, Diener PA \& Brandle M. New onset alopecia and hirsutism in a postmenopausal women. Gynecological Endocrinology 200925 324-327. (doi:10.1080/09513590902730788)

17 Di Giacinto P, Chioma L, Vancieri G, Guccione L, Cicerone E, Ulisse S, Mariani S, Autore C, Fabbri A, Gnessi L et al. Virilizing leydig-sertoli cell ovarian tumor associated with endometrioid carcinoma of the endometrium in a postmenopausal patient: case report and general considerations. Clinical Medicine Insights. Case Reports 20125 149-153.

18 Guo L, Yang X, Zhu H, Qiu W, Shi X, Huang B \& Duan T. SertoliLeydig cell tumor presenting hyperestrogenism in a postmenopausal woman: a case report and review of the literature. Taiwanese Journal of Obstetrics \& Gynecology 201251 620-624. (doi:10.1016/j. tjog.2012.09.019)

19 Marcondes JA, Nery M, Mendonca BB, Hayashida SA, Halbe HW, Carvalho FM \& Wajchenberg BL. A virilizing Leydig cell tumor of the ovary associated with stromal hyperplasia under gonadotropin control. Journal of endocrinological investigation 199720 685-689. (doi:10.1007/BF03348033)

20 journal Matuszczyk A, Petersenn S, Lahner H, Haude M, Veit P, Becker JU, Kimmig R, Bockisch A \& Mann K. [Leydig cell tumor as a cause of hirsutism in a postmenopausal woman]. Medizinische Klinik 2007102 259-262.

21 Paragliola RM, Torino F, Senes P, Castellino L, Salutari V, Pontecorvi A, Scambia G \& Corsello SM. "Occult" ovarian Leydig cell tumor: when laboratory tells more than imaging. Endocrine 201346 351-354. (doi:10.1007/s12020-013-0066-0)

22 Stacher E, Pristauz G, Scholz HS \& Moinfar F. Bilateral ovarian welldifferentiated Sertoli-Leydig cell tumors with heterologous elements associated with unilateral serous cystadenoma - a case report. International Journal of Gynecological Pathology 201029 419-422. (doi:10.1097/PGP.0b013e3181db69c7)

23 Stephens JW, Katz JR, McDermott N, MacLean AB \& Bouloux PM. An unusual steroid-producing ovarian tumour: case report. Human Reproduction 200217 1468-1471. (doi:10.1093/humrep/17.6.1468)

24 WHO. WHO Classification of Tumours of Female Reproductive Organs. edn 4th ed. Eds RJ Kurman, M Carcangiu, C Herrington \& R Young. Lyon: International Agency for Research on Cancer, 2014.

25 Hatch R, Rosenfield RL, Kim MH \& Tredway D. Hirsutism: implications, etiology, and management. American Journal of Obstetrics \& Gynecology 1981140 815-830. (doi:10.1016/00029378(81)90746-8)

26 Ludwig E. Classification of the types of androgenetic alopecia (common baldness) occurring in the female sex. British Journal of Dermatology 197797 247-254. (doi:10.1111/j.1365-2133.1977. tb15179.x) 
27 Horejsi J. Acquired clitoral enlargement. Diagnosis and treatment. Annals of the New York Academy of Sciences 1997816 369-372. (doi:10.1111/j.1749-6632.1997.tb52163.x)

28 Giacobbe M, Mendes Pinto-Neto A, Simoes Costa-Paiva LH \& Martinez EZ. The usefulness of ovarian volume, antral follicle count and age as predictors of menopausal status. Climacteric $2004 \mathbf{7}$ 255-260. (doi:10.1080/13697130410001713715)

29 Merz E, Miric-Tesanic D, Bahlmann F, Weber G \& Wellek S. Sonographic size of uterus and ovaries in pre- and postmenopausal women. Ultrasound Obstetrics \& Gynecology 19967 38-42.

30 Cohen HL, Tice HM \& Mandel FS. Ovarian volumes measured by US: bigger than we think. Radiology 1990177 189-192. (doi:10.1148/ radiology.177.1.2204964)

31 Markopoulos MC, Kassi E, Alexandraki KI, Mastorakos G \& Kaltsas G. Management of endocrine disease: hyperandrogenism after menopause. European Journal of Endocrinology 2014172 R79-R91. (doi:10.1530/EJE-14-0468)

32 32. Rousset P, Gompel A, Christin-Maitre S, Pugeat M, Hugol D, Ghossain MA \& Buy JN. Ovarian hyperthecosis on grayscale and color Doppler ultrasound. Ultrasound Obstetrics \& Gynecology 200832 694-699. (doi:10.1002/uog.6131)

33 Diamanti-Kandarakis E, Lambrinoudaki I, Economou F, Christou M, Piperi C, Papavassiliou AG \& Creatsas G. Androgens associated with advanced glycation end-products in postmenopausal women. Menopause 201017 1182-1187. (doi:10.1097/gme.0b013e3181e170af)

34 Liao Y, Huang R, Sun Y, Yue J, Zheng J, Wang L, Tao T, Ma J, Li S \& Liu W. An inverse association between serum soluble receptor of advanced glycation end products and hyperandrogenism and potential implication in polycystic ovary syndrome patients. Reproductive Biology and Endocrinology 201715 9. (doi:10.1186/s12958-017-0227-8)

35 Polotsky AJ, Allshouse AA, Crawford SL, Harlow SD, Khalil N, Kazlauskaite R, Santoro N \& Legro RS. Hyperandrogenic oligomenorrhea and metabolic risks across menopausal transition. Journal of Clinical Endocrinology and Metabolism 201499 2120-2127. (doi:10.1210/jc.2013-4170)
36 Pelusi C, Forlani G, Zanotti L, Gambineri A \& Pasquali R. No metabolic impact of surgical normalization of hyperandrogenism in postmenopausal women with ovarian androgen-secreting tumours. Clinical Endocrinology 201378 533-538. (doi:10.1111/j.13652265.2012.04438.x)

37 Maroulis GB. Evaluation of hirsutism and hyperandrogenemia. Fertility and Sterility 198136 273-305. (doi:10.1016/S00150282(16)45728-6)

38 Czajka-Oraniec I \& Simpson ER. Aromatase research and its clinical significance. Endokrynolog pol 201061 126-134.

39 Brodowska A, Brodowski J, Laszczynska M, Sluczanowska-Glabowska S, Rumianowski B, Rotter I, Starczewski A \& Ratajczak MZ. Immunoexpression of aromatase cytochrome P450 and 17betahydroxysteroid dehydrogenase in women's ovaries after menopause. Journal of Ovarian Research 20147 52. (doi:10.1186/1757-2215-7-52)

40 Brown DL, Henrichsen TL, Clayton AC, Hudson SB, Coddington CC, 3rd \& Vella A. Ovarian stromal hyperthecosis: sonographic features and histologic associations. Journal of Ultrasound in Medicine 200928 587-593. (doi:10.7863/jum.2009.28.5.587)

41 Kurjak A, Kupesic S \& Simunic V. Ultrasonic assessment of the periand postmenopausal ovary. Maturitas 200241 245-254. (doi:10.1016/ S0378-5122(01)00305-X)

42 Faria AM, Perez RV, Marcondes JA, Freire DS, Blasbalg R, Soares J, Jr., Simoes K, Hayashida SA \& Pereira MA. A premenopausal woman with virilization secondary to an ovarian Leydig cell tumor. Nature Reviews Endocrinology 20117 240-245. (doi:10.1038/nrendo.2011.15)

43 Wang PH, Chao HT, Liu RS, Cho YH, Ng HT \& Yuan CC. Diagnosis and localization of testosterone-producing ovarian tumors: imaging or biochemical evaluation. Gynecologic Oncology 200183 596-598. (doi:10.1006/gyno.2001.6412)

44 Mattsson C, Stanhope CR, Sam S \& Young WF, Jr. Image in endocrinology: testosterone-secreting ovarian tumor localized with (fluorine-18)-2-deoxyglucose positron emission tomography. Journal of Clinical Endocrinology and Metabolism 200691 738-739. (doi:10.1210/jc.2005-2270)

Received 8 Febraury 2017

Revised version received 31 March 2017

Accepted 21 April 2017 